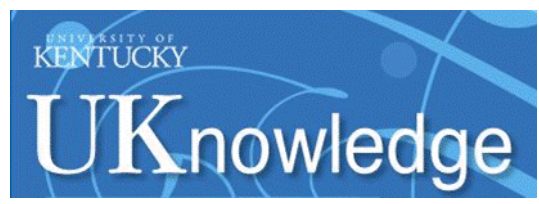

University of Kentucky

UKnowledge

\title{
Numerical Study of Spallation Phenomenon in an Arc-Jet Environment
}

\author{
Raghava Davuluri \\ University of Kentucky, raghava.sai.chaitanya@gmail.com
}

Alexandre Martin

University of Kentucky, alexandre.martin@uky.edu

Follow this and additional works at: https://uknowledge.uky.edu/me_facpub

Part of the Aerodynamics and Fluid Mechanics Commons, Computer Sciences Commons, and the Space Vehicles Commons

Right click to open a feedback form in a new tab to let us know how this document benefits you.

\section{Repository Citation}

Davuluri, Raghava and Martin, Alexandre, "Numerical Study of Spallation Phenomenon in an Arc-Jet Environment" (2014). Mechanical Engineering Faculty Publications. 11.

https://uknowledge.uky.edu/me_facpub/11

This Conference Proceeding is brought to you for free and open access by the Mechanical Engineering at UKnowledge. It has been accepted for inclusion in Mechanical Engineering Faculty Publications by an authorized administrator of UKnowledge. For more information, please contact UKnowledge@lsv.uky.edu. 
Numerical Study of Spallation Phenomenon in an Arc-Jet Environment

Digital Object Identifier (DOI)

http://dx.doi.org/10.2514/6.2014-2249

Notes/Citation Information

Published in the Proceedings of the 11th AIAA/ASME Joint Thermophysics and Heat Transfer Conference, Paper 2014-2249, p. 1-16.

Copyright $(\odot 2014$ by Raghava Davuluri and Alexandre Martin.

The copyright holders have granted the permission for posting the article here. 


\title{
Numerical study of spallation phenomenon in an arc-jet environment
}

\author{
Raghava Davuluri* and Alexandre Martin $\dagger$ \\ University of Kentucky, Lexington, KY, 40506, USA
}

\begin{abstract}
The spallation phenomenon might affect the aerodynamic heating rates of re-entry vehicles. To investigate spallation effects, a code is developed to compute the dynamics of spalled particles. The code uses a finite-rate chemistry model to study the chemical interactions of the particles with the flow field. The spallation code is one-way coupled to a CFD solver that models the hypersonic flow field around an ablative sample. Spalled particles behavior is numerically studied for argon and air flow field. The chemistry model is compared with that of Park's model which complies with oxidation and sublimation and shows disagreement for nitridation.
\end{abstract}

\section{Introduction}

A BLATIVE materials are used as the Thermal Protection System (TPS) for space vehicles that enter a A planetary atmosphere. During the entry phase, the vehicle experiences high rates of aerodynamic heating. These ablative materials, acting as a heat shield, protect the vehicle from such harsh environments and ensure a safe entry. They reduce the incoming heat flux through various phenomena such as nearsurface oxidation, pyrolysis chemical reaction, vaporization, and other erosive processes, collectively known as ablation. Spallation is defined as one such process where solid particles are ejected from the material into the flow field. Spalled particles are generally formed by soot, a product of the pyrolysis process. They could also be produced by disconnected fibers or chunks of material ejected by thermal or inner pressure stress.

Though the spalled particles carry away heat, their presence in the upstream and downstream regions of the shock layer further affect the heating at the surface. When compared with theoretical analysis, experimentally measured heating/ablating rates for heat shields of Pioneer-Venus ${ }^{1}$ and Galileo probes ${ }^{2,3,4}$ showed disagreements. The rates were under-predicted at the stagnation point and over-predicted in the downstream region. Spallation was regarded as one possible mechanism that caused these discrepancies. Furthermore, the spectroscopic measurements by Raiche et. al. ${ }^{5}$ observed continuum radiation, especially in the upstream region of the shock. The radiation corresponded to a black body spectrum which was due to the presence of spalled particles. ${ }^{6}$ Also, spectroscopic measurements by Kihara et. al. ${ }^{7}$ and Yoshinaka et. al. $^{8}$ demonstrated the presence of $\mathrm{CN}$ emission spectra in the inviscid region, particularly ahead of the shock. Only carbonaceous spalled particles can reach a distance that far from the sample, which is most likely the reason for the presence of $\mathrm{CN}$.

The spalled particles vaporize along their path and tend to alter the aerodynamic heat rates by changing the chemical composition of the flow field which enhances the radiation effects. In addition, the spalled particle dynamics relative to flow field regime result in an increase in turbulent effect which also increases the heat rates. Hence, it is important to study this phenomenon and evaluate if it is significant in order to design an efficient TPS.

A limited amount of work has been done, both experimentally and numerically, to assess the effect of spallation phenomena. Lundell ${ }^{9}$ experimentally investigated the spallation mass losses on a particle canister and correlated it to Galileo probe heating conditions to estimate the losses for its heat shield. Davies et. al. ${ }^{10}$ developed a numerical solution technique to compute trajectories of a spalled particle with vaporizing mass.

${ }^{*}$ Graduate Student, Department of Mechanical Engineering, AIAA Student Member

${ }^{\dagger}$ Assistant Professor, Department of Mechanical Engineering; Associate Faculty at the Center for Computational Science, Senior Member AIAA. alexandre.martin@uky.edu 
The results were correlated to the Galileo probe flow field solution. Park ${ }^{11,6}$ used a numerical integration method on the equation of motion of spalled particle to calculate the trajectory of spalled particle with vaporizing mass. He determined lower limits for size and initial velocity for which particles penetrate the shock by comparing with the results of Raiche et. al. ${ }^{5}$ and Yoshinaka et. al. ${ }^{8}$ Recently, Pace et. al. ${ }^{12}$ computed particle densities using "bins" of spalled particles of same size and constant mass, through an Eulerian frame of reference integrated into a CFD code. ${ }^{13}$ This was followed by the work of Nozawa et. al., ${ }^{14}$ who performed simulation to compute the single spalled particle trajectory with vaporizing mass. They determined the lower limits for size and initial velocity of the particles that penetrate through the shock based on the observations made during the experiments performed by Kihara et. al. ${ }^{7}$

In the present work, a particle-tracking code is developed to compute the spalled particle properties and trajectory as it is ejected from the surface. This work integrates the techniques developed by Davies et. al., ${ }^{10}$ Pace et. al. ${ }^{12}$ and Nozawa et. al. ${ }^{14}$ The code uses the solution of a Computational Fluid Dynamic (CFD) code (one-way coupling) to simulate a high enthalpy gas flow field in arc-jet environment, over a light weight ablative test piece. $^{15}$

\section{Governing Equations and Physical Models}

\section{Governing Equations}

The developed spallation code computes the dynamics of a single particle ejected from the surface and only accounts for the interaction of the particle with the flow field. The following assumptions are considered to simplify the approach:

1. the particle is a graphite sphere.

2. heat and mass transfer is uniform around the surface of the particle.

3. physical properties of the particle are assumed to be constant.

A Lagrangian formulation is employed to compute the projected path of the spalled particle and corresponding governing equations are of the form:

$$
\frac{D \mathbf{U}}{D \mathrm{t}}=\frac{\partial \mathbf{U}}{\partial \mathrm{t}}=\mathbf{S}
$$

where $\mathbf{U}$ is the state vector and $\mathbf{S}$ is the source vector matrix. The elements of $\mathbf{U}$, which denote the conserved variables are:

$$
\mathbf{U}=\left(\begin{array}{c}
m_{p} \\
m_{p} u_{p} \\
\mathrm{~m}_{\mathrm{p}} \mathrm{v}_{\mathrm{p}} \\
m_{p} w_{p} \\
m_{p} E_{p}
\end{array}\right)
$$

where $\mathrm{m}_{\mathrm{p}}$ is the mass of the particle, $\left(u_{p}, v_{p}, w_{p}\right)$ are the components of velocity of the particle, and $E_{p}$ is the internal energy of the particle.

\section{Physical Models}

It is assumed that the most important force acting on the particle is drag force generated by the flow field, and all other forces are neglected, such as gravitational and buoyancy forces. The motion of the particle in axial direction is described by

$$
\frac{\partial}{\partial t}\left(m_{p} u_{p}\right)=F_{D_{x}}=\frac{1}{2} C_{D} \rho_{f} A_{p}\left(u_{f}-u_{p}\right) V_{r}
$$

where $C_{D}$ is the drag coefficient, $\rho_{f}$ is the density of the flow field, $A_{p}$ is the cross-section of the particle, $V_{r}$ is the relative velocity, and $u_{f}$ is the velocity of flow field in axial direction. Similar formulation is taken for the motion of the particle in other directions. The drag coefficient $C_{D}$ used in the Eq. 3 is calculated using 
Henderson ${ }^{16}$ model. This model is valid for flows ranging from continuum to free molecular flow, which also includes slip and transition flows, and can be applied to Mach number up to 6 . It also considers the effect of particle temperature and flow field temperature on the drag coefficient. The drag coefficient $C_{D}$ equation is

$$
C_{D}=\left\{\begin{aligned}
24\left[\operatorname{Re}+S\left\{4.33+\frac{3.65-1.53\left(\frac{T_{p}}{T_{f}}\right)}{1+0.353\left(\frac{T_{p}}{T_{f}}\right)} \exp \left(-0.247 \frac{\mathrm{Re}}{S}\right)\right\}\right] & \\
\quad+\exp \left(-\frac{0.5 \mathrm{M}}{\sqrt{\mathrm{Re}}}\right)\left[\frac{4.5+0.38(0.03 \mathrm{Re}+0.48 \sqrt{\mathrm{Re}})}{1+0.03 \mathrm{Re}+0.48 \sqrt{\mathrm{Re}}}+0.1 \mathrm{M}^{2}+0.2 \mathrm{M}^{8}\right] & \text { if } \mathrm{M} \leq 1 \\
\quad+0.6 S\left[1-\exp \left(-\frac{\mathrm{M}}{\mathrm{Re}}\right)\right] & \text { if } 1<\mathrm{M} \leq 1.75 \\
C_{D_{(\mathrm{M}=1)}+\frac{4}{3}(\mathrm{M}-1)\left(C_{D_{(\mathrm{M}=1.75)}}-C_{\left.D_{(\mathrm{M}=1)}\right),}\right.} & \\
0.9+\left(\frac{0.34}{\mathrm{M}^{2}}\right)+1.86\left(\frac{\mathrm{M}}{\mathrm{Re}}\right)^{\frac{1}{2}}\left[2+\frac{2}{S^{2}}+\frac{1.058}{S}\left(\frac{T_{p}}{T_{f}}\right)^{\frac{1}{2}}-\frac{1}{S^{4}}\right] & \text { if } \mathrm{M}>1.75
\end{aligned}\right.
$$

where $\mathrm{M}$ is the Mach number, Re is the Reynolds number based on relative velocity, and $S$ is Molecular speed ratio. The dynamic viscosity $(\mu)$ used in the Reynolds number is calculated from Wilke's semi-empirical mixing rule ${ }^{17}$ where Blottner's curve fits ${ }^{18}$ are used to calculate the individual species viscosities.

The internal energy of the particle, which is the sum of the specific heat and kinetic energy, is transferred in the form of power drag, convective heat rate, radiative heat rate and heat rate due to the reaction at the surface of the particle. It is formulated as

$$
\frac{\partial}{\partial t}\left(m_{p} E_{p}\right)=\frac{\partial}{\partial t}\left[m_{p} C_{v_{p}} T_{p}+\frac{1}{2} m_{p}\left(u_{p}^{2}+v_{p}^{2}+w_{p}^{2}\right)\right]=\dot{q}_{c o n v}+p_{d r a g}-\dot{q}_{r a d}+\dot{q}_{r x n}
$$

where $C_{v_{p}}$ is the specific heat at constant volume of the particle, $T_{p}$ is the temperature of the particle, $\dot{q}_{c o n v}$ is the convective heat rate transferred, $p_{d r a g}$ is the drag power, $\dot{q}_{r a d}$ is the radiative heat rate from the particle, and $\dot{q}_{r x n}$ is the heat rate produced by the reaction at the surface of the particle. Drag power is the rate of work done by the particle to overcome the drag force acting on it and is given as

$$
p_{\text {drag }}=\frac{1}{2} C_{D} \rho_{f} A_{p} V_{r}^{3}
$$

The radiative heat rate from the particle is evaluated using the Stefan-Boltzmann law integrated over the surface of the particle

$$
\dot{q}_{\text {rad }}=\epsilon \sigma T_{p}^{4} A_{s}
$$

where $\epsilon$ is the emissivity of the particle, $\sigma$ is the Stefan-Boltzmann constant, and $A_{s}$ is the surface area of the particle. The convective heat transfer into the particle is the heat conducted from flow field to it and its rate is given as

$$
\dot{q}_{\text {conv }}=\mathrm{Nu} \frac{\left[\kappa_{t r}\left(T_{f_{t r}}-T_{p}\right)+\kappa_{v e}\left(T_{f_{v e}}-T_{p}\right)\right]}{d_{p}} A_{s}
$$

where $\mathrm{Nu}$ is the Nusselt number, $\kappa$ is the thermal conductivity of the flow field, $T_{f}$ is the flow field temperature, and subscripts $t r$ and ve denote translational-rotational energy mode and vibrational-electronic energy mode, respectively. The Nusselt number Nu used in Eq. 8 is evaluated by using Carlson and Hoglund model $^{19}$ given as

$$
\mathrm{Nu}=\frac{2+0.459 \mathrm{Re}^{0.55}}{1+3.42 \frac{\mathrm{M}}{\mathrm{Re}}\left(2+0.459 \mathrm{Re}^{0.55}\right)}
$$


and the thermal conductivity of the flow field is calculated using Wilke's semi-empirical mixing rule ${ }^{17}$ where Eucken's relation ${ }^{20}$ is used to calculate individual species thermal conductivities present in the flow field. The reactions occurring on the surface of the particle are oxidation and nitridation due to the presence of $\mathrm{O}, \mathrm{O}_{2}$ and $\mathrm{N}$ in the flow field. Also, the particle is subjected to sublimation with its increase in temperature. Hence, the heat rate produced by the surface reaction can be expressed as

$$
\dot{q}_{r x n}=\dot{q}_{\mathrm{O}}+\dot{q}_{\mathrm{N}}-\dot{q}_{\mathrm{O}_{2}}-\dot{q}_{s u b}
$$

where $\dot{q}_{\mathrm{O}}$ is the rate of heat produced by oxidation of particle surface with atomic oxygen $(\mathrm{O}), \dot{q}_{\mathrm{O}_{2}}$ is the rate of heat produced by oxidation of particle surface with molecular oxygen $\left(\mathrm{O}_{2}\right)$, and $\dot{q}_{\mathrm{N}}$ is the rate of heat produced by nitridation of particle surface with atomic nitrogen $(\mathrm{N})$. The heat rate produced by these surface reactions ${ }^{21}$ on the particle is evaluated as

$$
\dot{q}_{\mathrm{O}, \mathrm{O}_{2}, \mathrm{~N}}=A_{s}\left(\sum \Delta h \frac{\bar{\nu}_{i} c_{i}}{4}\right)
$$

where $\Delta h$ is the enthalpy of a reaction, $c_{i}$ is the local concentration at particles surface, and $\bar{\nu}_{i}$ is the mean thermal speed of species i $\left(=\mathrm{O}, \mathrm{O}_{2}, \mathrm{~N}\right)$. However, the sublimation of the particle depends exclusively on the temperature of the particle. The heat rate produced by the sublimation is given by

$$
\dot{q}_{s u b}=A_{s}\left(\sum \Delta G_{f} \dot{m}_{\mathrm{C}_{\mathrm{i}}}\right)
$$

where $\Delta G_{f}$ is the Gibbs free energy of formation, and $\dot{m}_{\mathrm{C}_{\mathrm{i}}}$ is the vapor flux of $\mathrm{C}_{\mathrm{i}}$ species formed. Standard Gibbs free energy of formation is interpolated from the JANAF tables ${ }^{22}$ at the temperature of the particle, and $\Delta G_{f}$ is calculated at the pressure of the $\mathrm{C}_{\mathrm{i}}$ vapor, which is calculated using Eq. 18.

\section{Particle Surface Reactions}

The possible reactions occurring on the spalled particle, as mentioned earlier, are oxidation, nitridation and sublimation. The oxidation by atomic and molecular oxygen at the surface of the spalled particle are given by forward (irreversible) reactions:

$$
\begin{gathered}
\mathrm{C}_{(\mathrm{s})}+\mathrm{O} \longrightarrow \mathrm{CO} \\
2 \mathrm{C}_{(\mathrm{s})}+\mathrm{O}_{2} \longrightarrow 2 \mathrm{CO}
\end{gathered}
$$

The oxidation by atomic oxygen is an exothermic reaction whereas that by molecular oxygen is an endothermic reaction. As for the nitridation by atomic nitrogen, it is given by the following exothermic forward reaction:

$$
\mathrm{C}_{(\mathrm{s})}+\mathrm{N} \longrightarrow \mathrm{CN}
$$

The mass rate of the receding particle due to oxidation and nitridation can be computed as

$$
\begin{gathered}
\dot{m}_{\mathrm{C} / \mathrm{CO}}=M_{\mathrm{C}}\left(k_{f_{\mathrm{O}}} c_{\mathrm{O}}+k_{f_{\mathrm{O}_{2}}} c_{\mathrm{O}_{2}}\right) A_{s} \\
\dot{m}_{\mathrm{C} / \mathrm{CN}}=M_{\mathrm{C}}\left(k_{f_{\mathrm{N}}} c_{\mathrm{N}}\right) A_{s}
\end{gathered}
$$

where $M_{i}$ is the molar weight of the species $i, c_{i}$ is the local concentration of species $i$, and $k_{f_{i}}$ is the forward reaction rate constant. It is assumed that the atomic oxygen, molecular oxygen, and atomic nitrogen impinge on the surface of the particle and directly form the products. Thus, the adsorption steps are not considered. As the particle is in motion, it is assumed that the reactions are forward in nature, and no backward reactions are considered. The forward reaction rate constant can be expressed as

$$
k_{f}=\frac{\gamma_{0}}{4}\left[\bar{\nu}+V_{r}\right] \exp \left(-\frac{E}{R T}\right)
$$

where $\bar{\nu}_{i}$ is the thermal speed of the species $i, \gamma_{0}$ is the reaction efficiency, and $E$ is the energy barrier for reaction. Thermal speed of species $i$ is given as

$$
\bar{\nu}_{i}=\sqrt{\frac{8 R T_{f}}{\pi M_{i}}}
$$


Table 1. Values of $\gamma_{0}$ and $E$ for the following reactions according to Driver's surface chemistry model

\begin{tabular}{ccc}
\hline Reactions & $\gamma_{0}$ & $E(\mathrm{~kJ} / \mathrm{mol})$ \\
\hline \hline $\mathrm{C}_{(\mathrm{s})}+\mathrm{O} \longrightarrow \mathrm{CO}$ & 0.90 & 0 \\
$2 \mathrm{C}_{(\mathrm{s})}+\mathrm{O}_{2} \longrightarrow 2 \mathrm{CO}$ & 0.01 & 0 \\
$\mathrm{C}_{(\mathrm{s})}+\mathrm{N} \longrightarrow \mathrm{CN}$ & 0.005 & 0 \\
\hline
\end{tabular}

In the above expression, $T_{f}$ is the flow field temperature. Since the CFD code uses a two-temperatures model of accounting for thermal non-equilibrium in the flow field, for that expression, only the translational temperature is considered. The values of $\gamma_{0}$ and $E$ are taken from Driver et. al ${ }^{23,24}$ which are given in Table 1. Driver et. al performed experimentations on a Fiberform sample and evaluated constant reaction efficiencies for oxidation reactions. The nitridation reaction is neglected due to a very low production rate in this model. However, the reaction efficiency constant for nitridation is taken from their experimental results and used in the code to compare the production rates with Park's model. ${ }^{11,6,25}$ Similarly, sublimation is not considered in Driver et. al model as temperatures were lower than the sublimation temperatures. Since the particle has to travel through a very high temperature flow field, sublimation is considered in this work, and its model is given below. For sublimation, the following irreversible forward reactions are considered to occur in this model:

$$
\begin{aligned}
\mathrm{C}_{(\mathrm{s})} & \longrightarrow \mathrm{C}_{(\mathrm{g})} \\
2 \mathrm{C}_{(\mathrm{s})} & \longrightarrow \mathrm{C}_{2(\mathrm{~g})} \\
3 \mathrm{C}_{(\mathrm{s})} & \longrightarrow \mathrm{C}_{3(\mathrm{~g})}
\end{aligned}
$$

These reactions are endothermic in nature. The total mass of particle receded due to the sublimation process is calculated using Knudsen-Langmuir equation: ${ }^{26}$

$$
\dot{m}_{\mathrm{C} / s u b}=\sum \dot{m}_{\mathrm{C}_{\mathrm{i}}}=\sum \alpha_{v_{i}} P_{c_{i}} \sqrt{\frac{M_{i}}{2 \pi R T_{p}}} A_{s}
$$

where $\alpha_{v_{i}}$ is the vaporization coefficient ${ }^{27}$ of species $i, M_{i}$ is the molar weight of species $i, P_{c_{i}}$ vapor pressure of the carbon vapor formed from $C_{i}$ species, and $R$ is the universal gas constant. The vapor pressure is calculated using Clausius-Clapeyron equation, and the values of the constants are taken from the thermochemical data of Palmer and Shelef. ${ }^{28}$

$$
\ln P_{\mathrm{c}_{\mathrm{i}}}=\frac{A}{T_{p}}+B
$$

The global recession mass rate of the spalled particle can therefore be expressed as

$$
\frac{\partial m_{p}}{\partial t}=\dot{m}_{p}=\dot{m}_{\mathrm{C} / \mathrm{CO}}+\dot{m}_{\mathrm{C} / \mathrm{CN}}+\dot{m}_{\mathrm{C} / s u b}
$$

Inserting Eqs. 3, 10 and 19 into Eq. 2, the system of equation to be solved is therefore:

$$
\frac{\partial}{\partial t}\left(\begin{array}{c}
m_{p} \\
m_{p} u_{p} \\
m_{p} v_{p} \\
m_{p} w_{p} \\
m_{p} E_{p}
\end{array}\right)=\left(\begin{array}{c}
-\dot{m}_{\mathrm{C} / \mathrm{CO}-\dot{m}_{\mathrm{C} / \mathrm{CN}}-\dot{m}_{\mathrm{C} / s u b}} F_{D_{x}} \\
F_{D_{y}} \\
F_{D_{z}} \\
\dot{q}_{c o n v}+p_{d r a g}-\dot{q}_{r a d}+\dot{q}_{r x n}
\end{array}\right)
$$

\section{Flow Field}

The flow field is computed using the hypersonic aerothermodynamic CFD code KATS ${ }^{29}$ developed at the University of Kentucky. It computes the hypersonic flow field that surrounds the ablator sample. The test 
cases considered in this paper consist of Mach 5 high enthalpy flow over a light weight ablator as shown in Fig. 1. Two gases are considered: argon and air. The argon flow field is non-reacting, and hence, only sublimation of the particle takes place. Since argon is a monoatomic molecule, no vibrational energy is calculated, and only translational temperature is computed.

For the air flow field, 6 species are taken into account: $\mathrm{Ar}, \mathrm{N}_{2}, \mathrm{O}_{2}, \mathrm{NO}, \mathrm{O}$ and $\mathrm{N}$. Hence, the particle undergoes oxidation and nitridation along with the sublimation process.

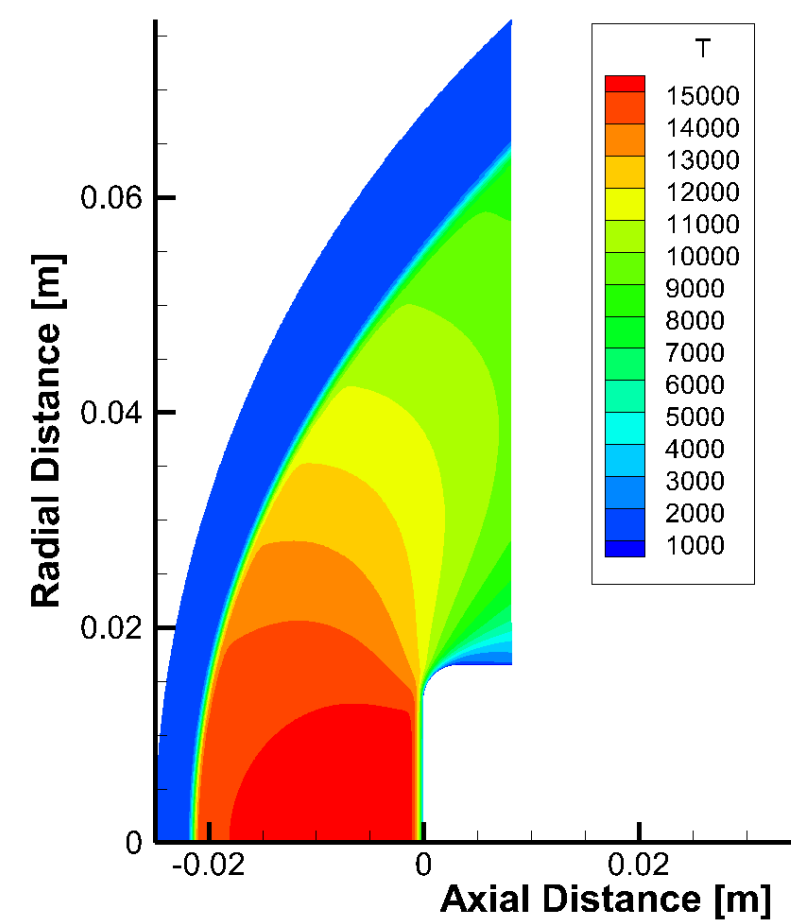

(a) Argon

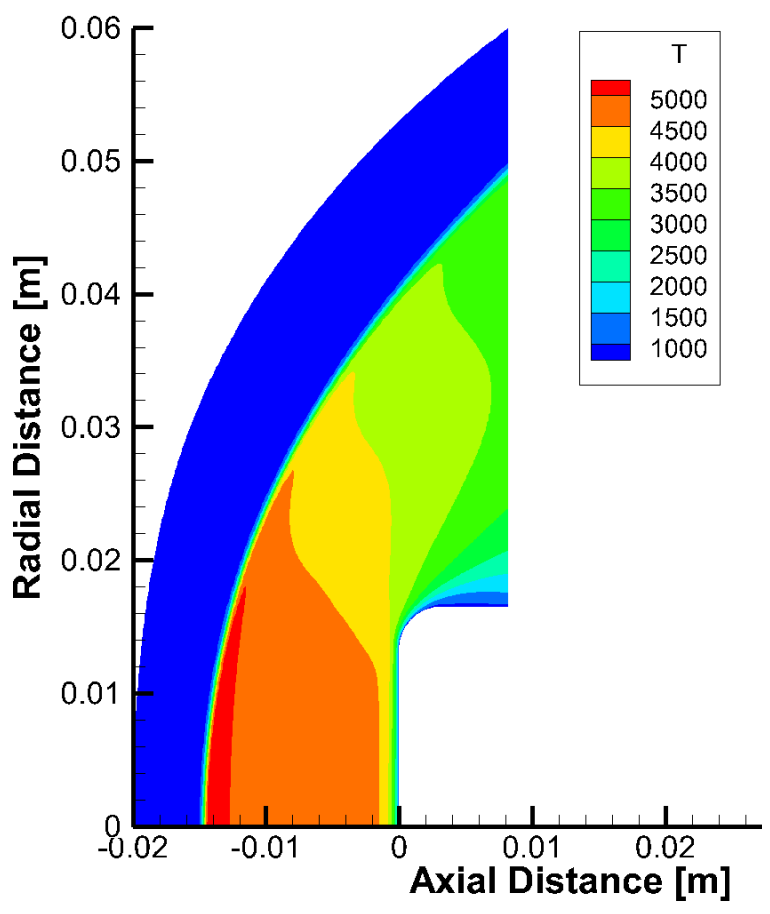

(b) Air

Figure 1. Mach 5 high enthalpy flow field around an ablative test piece

\section{Numerical Approach}

Equation 20 is discretized using a backward Euler method. The mass conservation equation is uncoupled from the momentum and energy conservation equations, and both sets of equation are solved using Block Gauss-Seidel method. The momentum and energy equations are solved using Newton's method. The output of these, the temperature of the particle, is inserted in the mass conservation equation to obtain the new diameter/mass, again using Newton's method for solving the equation. The new computed mass is re-inserted again in the momentum and energy equations, and new values are computed. This process is repeated until the relative error between the computed values of two successive iterations lower than $10^{-6}$.

Additionally, the position vector matrix is inserted in the system of equations to compute the trajectory of the spalled particle. This is an initial value problem where the radius, ejection velocity, ejection position, ejection angle and temperature of the particle have to be assigned. The initial temperature of the particle is assumed to be the temperature of the surface from which it gets ejected which is dictated from the flow field data.

The system of equation that is numerically solved is therefore: 


$$
\frac{\partial}{\partial t}\left(\begin{array}{c}
m_{p} \\
m_{p} u_{p} \\
m_{p} v_{p} \\
m_{p} w_{p} \\
m_{p} E_{p} \\
x_{p} \\
y_{p} \\
z_{p}
\end{array}\right)=\left(\begin{array}{c}
-\dot{m}_{\mathrm{C} / \mathrm{CO}}-\dot{m}_{\mathrm{C} / \mathrm{CN}}-\dot{m}_{\mathrm{C} / s u b} \\
F_{D_{x}} \\
F_{D_{y}} \\
F_{D_{z}} \\
\dot{q}_{c o n v}+p_{d r a g}-\dot{q}_{r a d}+\dot{q}_{r x n} \\
u_{p} \\
v_{p} \\
w_{p}
\end{array}\right)
$$

\section{A. Verification}

The developed code is verified by using Method of Manufactured Solutions (MMS). ${ }^{30}$ Each variables in the elements of state vector matrix $\mathbf{U}$ are expressed by a smooth functions, also called a manufactured solution, and processed in the governing equations. This provides an analytical solution. The smooth functions are then inserted into the discretized equations of the code. Numerical tests are performed on the code obtaining a solution using various time steps and comparing with the analytical solution. The error between the solutions is examined against the theoretical order of accuracy based on the discretization performed in the code. In the present case, the accuracy is first order.

The manufactured solution considered in this code is an exponential function of the form:

$$
\mathbf{U}=a e^{b t}+c
$$

where $a, b, c$ are constant parameters, and $t$ represents time. Table 2 lists the values considered for each parameters.

Table 2. Parameter values for different variables used in the manufactured solution

\begin{tabular}{cccc}
\hline Variables & $\mathrm{a}$ & $\mathrm{b}$ & $\mathrm{c}$ \\
\hline \hline$d_{p}$ & -1.0 & 0.05 & 2.0 \\
$T_{p}$ & 10.0 & 0.5 & 1000.0 \\
$u_{p}$ & -1.0 & 1.0 & 0.0 \\
$v_{p}$ & 5.0 & 0.5 & 0.0 \\
$w_{p}$ & -0.01 & -1.0 & 0.0 \\
\hline
\end{tabular}

Figure 2 shows the $L_{2}$ and maximum norm errors calculated between the analytical and numerical solutions. It is seen that the errors at different time steps are connected through a line of slope 2 which retains the first order accuracy according to convergence tests.

\section{Results and Discussions}

The particles trajectory behavior can be classified into two types - particles interacting with the shock and particles not interacting with shock. Among the particles that interact with the shock, some might re-enter the post shock region, some might completely vaporized, or some might be convected away in free stream. The particles which hardly vaporize do not generate any significant radiation effect on the sample whereas the particles which vaporize along their path tend to produce species which show radiative emittance irrespective of whether they interact with the shock or not. The species that reacts downstream of the shock might combine with other available species or dissociate because of the high temperature. On the other side, the species produced upstream of the shockwave tend to enhance the radiative heating.

The minimum ejection velocity required by the particle to pass throughout the shock is calculated. As the spectroscopic measurements are performed at a point upstream of the shock wave, these calculations could help us assess the minimum mechanical energy at the time of ejection from the sample and minimum amount of vapor products it leaves in the flow regime while it traverses its path. The results could also 


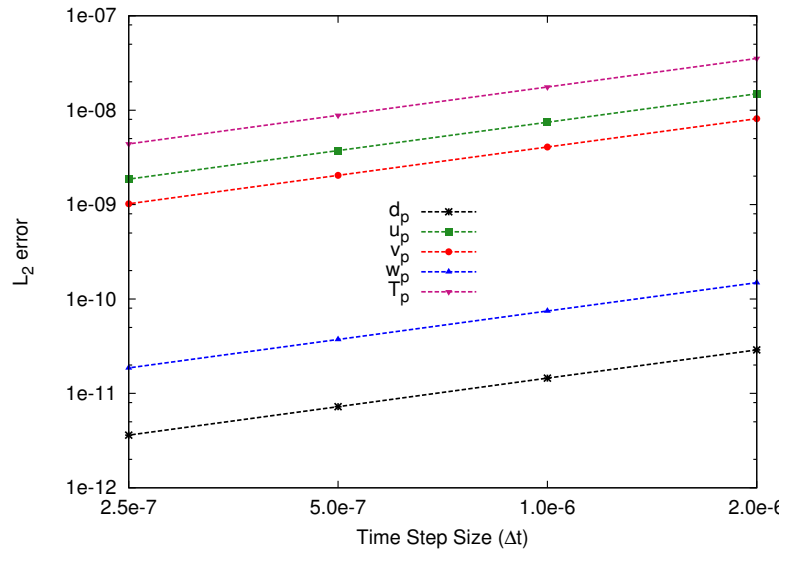

(a) $L_{2}$ norm error

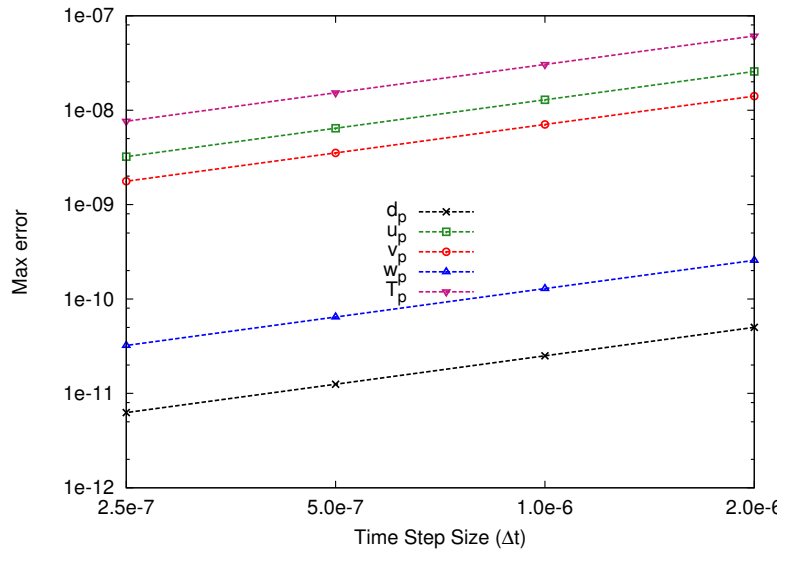

(b) Maximum norm error

Figure 2. Plots of $L_{2}$ norm error and maximum norm error

provide an estimate of the strength of fibers in the sample, which could be used to manufacture adapted ablative material. Minimum vapor products generated by a single spalled particle would be used in evaluating the radiative heating quantitatively.

It is important to point out that the $p_{d r a g}$ term in Eq. 5 plays an important role in the spalled particle trajectory. The Reynolds number of the spalled particle is very low due to their small size. Hence, the coefficient of drag is high and the particle has to provide a lot of energy to move against the drag force.

\section{A. Argon Flow Field}

As seen in Fig. 1(a), the Mach 5 flow field is a very high temperature zone and spalled particles undergo only sublimation. Due to a very low thermal conductivity of argon, it is observed that for most of the particle sizes, the surface temperature does not reach the sublimation temperatures. Hence, the particles travel without any recessions. The maximum size of the particle for which recession takes place is $16 \mu \mathrm{m}$. Also, the particles need a very high ejection velocity to penetrate through the shock layer. For example, a particle of diameter $16 \mu \mathrm{m}$ needs a minimum ejection velocity of $320 \mathrm{~m} / \mathrm{s}$ to penetrate through the shock, and it experiences a percentage change of $0.35 \%$ in the diameter throughout its travel. Further, smaller size particles need higher ejection velocities to penetrate through the shock. However, particles less than $10 \mu \mathrm{m}$ travel very close to the surface of the sample. Their radiative impact is not of greater importance as other ablation mechanisms near the surface provide a greater effect on the sample. Figure 3 shows the variation of minimum ejected velocities required by the particles to penetrate the shock as a function of the diameter of the particle ejected normal from the surface, at $7 \mathrm{~mm}$ from the center axis.

Figure 4(a) shows the trajectory of a spalled particle of initial diameter $14 \mu \mathrm{m}$ ejected at a velocity of 370 $\mathrm{m} / \mathrm{s}$ normal to the sample surface from point $13 \mathrm{~mm}$ from the center axis. The variation of temperature and diameter of the particle, as well as the variation of energy terms as a function of the particles trajectory are shown in Figs. 4(b) and 4(c). It is observed that the sudden changes in the particle temperature slope occurs when particle interacts with the shock wave. When the particle is upstream of the shock, the re-radiative energy plays a prominent role among all the energy source terms.

It is to be noted that the jagged results present in Fig. 4(c), and in subsequent plots, is not caused by the numerical model, but by the fact that no spatial interpolation is performed when transferring the flow field properties to the trajectory code. The properties in the outputted CFD mesh are assumed to be constant in each cell; therefore, as the particles travel from one cell to an other, the properties change abruptly. Although it is not expected that the results change much, the data would at least look nicer if an the field properties were interpolated. 


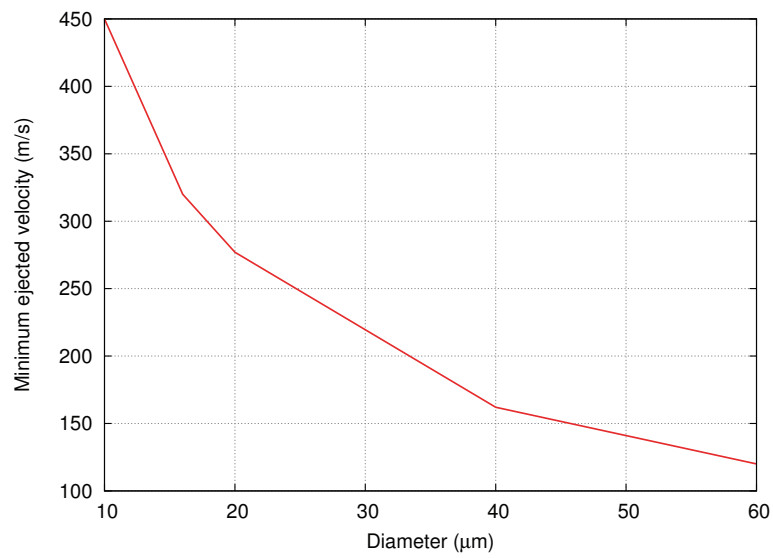

Figure 3. Variation of minimum ejected velocity with diameter for Argon Flow Field

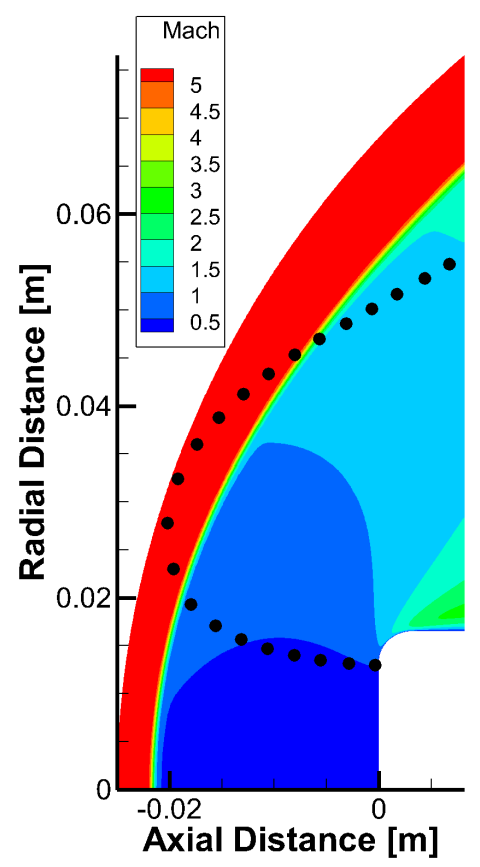

(a) Trajectory of the spalled particle 


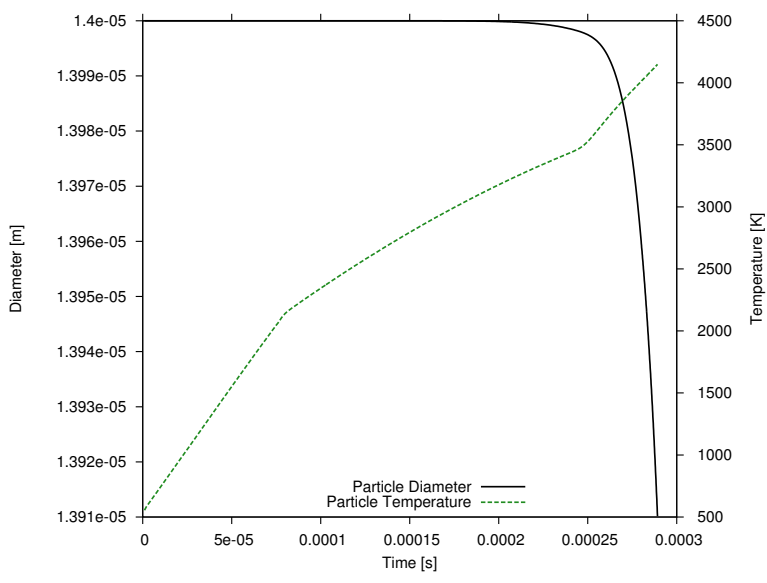

(b) Variation of diameter and temperature

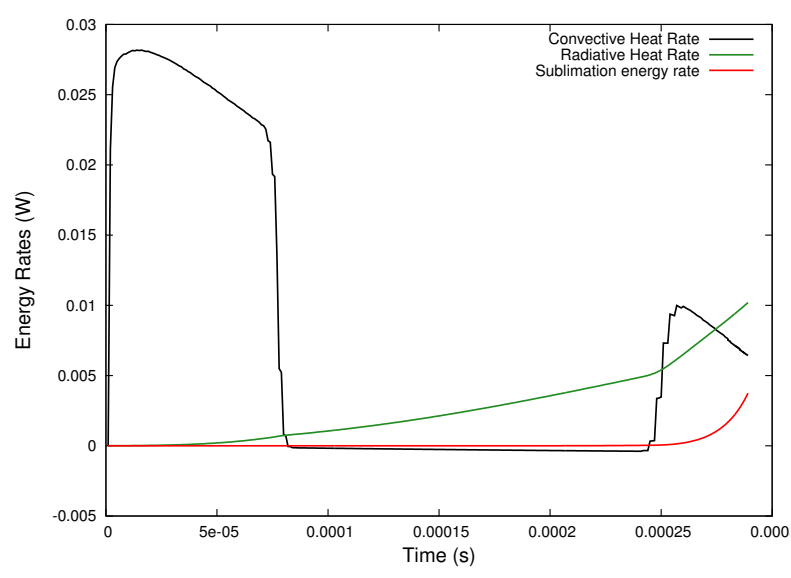

(c) Variation of rates of different heat and energies

Figure 4. Trajectory and variations of diameter, temperature and heat energy rate terms of the spalled particle as a function of time

\section{B. Air Flow Field}

In air flow field, the spalled particle undergoes oxidation, nitridation, and sublimation. The minimum ejection velocity needed to penetrate the shock is less than in the argon flow field. For example, a particle of diameter $10 \mu \mathrm{m}$ needs a minimum velocity of $150 \mathrm{~m} / \mathrm{s}$ to penetrate through the shock in air flow, whereas it need $450 \mathrm{~m} / \mathrm{s}$ in argon flow field. However, the particles of size less than $6 \mu \mathrm{m}$ require a very high ejection velocity to pass through the shock. Figure 5 shows the variation of minimum ejected velocities needed to penetrate the shock as a function of the diameter of the particle ejected normal from the surface, at $7 \mathrm{~mm}$ from the center axis of the sample.

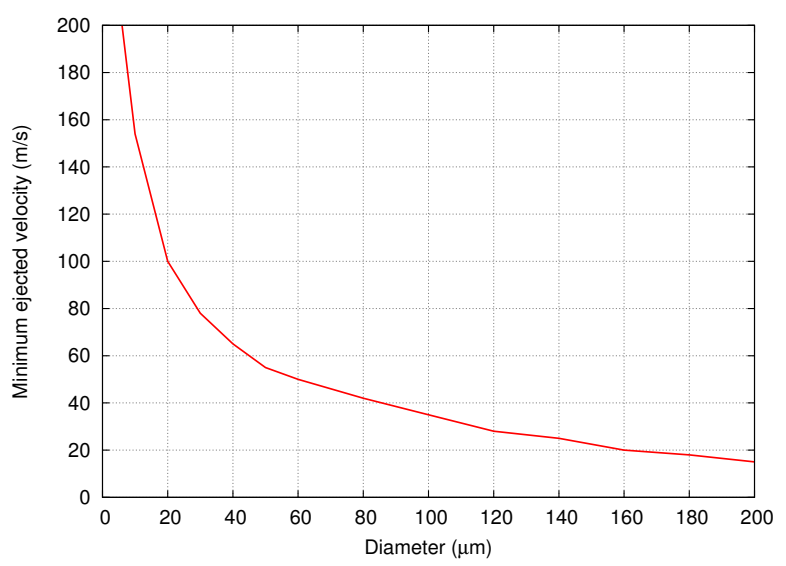

Figure 5. Variation of minimum ejection velocity with diameter for Air Flow Field

The oxidation rates are high for a spalled particle when compared to nitridation and sublimation. The very low $\gamma_{0}$ value for nitridation reaction ensures a very low rate of its production. However, the particle undergoes high oxidation and nitridation near the surface of the sample due to high concentration of species at the wall. The particle hardly sublimates as the particle does not reach the sublimation temperature. Figure 6(a) shows the trajectories of the spalled particles of sizes $10 \mu \mathrm{m}, 15 \mu \mathrm{m}$ and $20 \mu \mathrm{m}$ ejected at a velocity of $120 \mathrm{~m} / \mathrm{s}$ normally from a point $3 \mathrm{~mm}$ from the center axis. The $10 \mu \mathrm{m}$ particle does not interact with the shock whereas the $15 \mu \mathrm{m}$ particle interacts with the shock but does not pass through it. As for the $20 \mu \mathrm{m}$ particle, it does penetrate the shock and returns back. Figures 6(b), (c) and (d) demonstrate 
the variation of production rates of $\mathrm{CO}, \mathrm{CN}$ and carbon vapor $\left(\mathrm{C}_{1}, \mathrm{C}_{2}, \mathrm{C}_{3}\right)$ as a function of the size of the spalled particle. The behavior of oxidation and nitridation curves directly depend on the concentration of these species in the flow field. It can be seen that there is an abrupt change when the particle crosses the shock. In the free stream region, production rate is constant due to a concentrations of $\mathrm{O}$ and $\mathrm{N}$ close to zero, and very little $\mathrm{O}_{2}$.

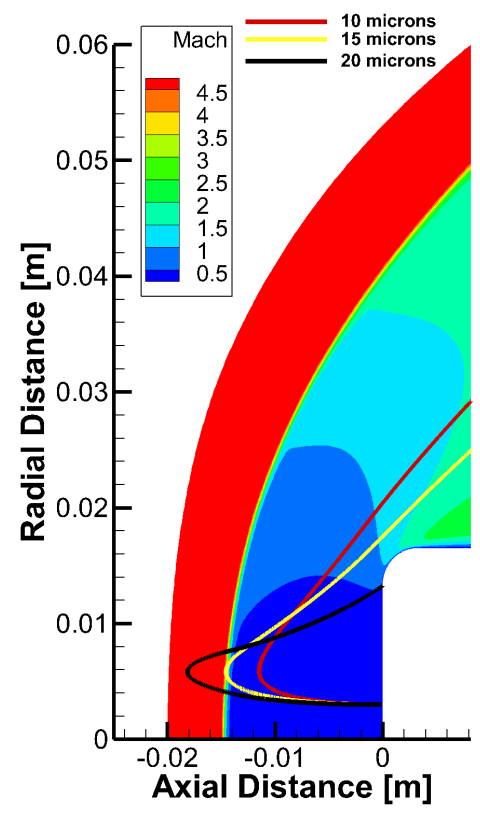

(a) Trajectory

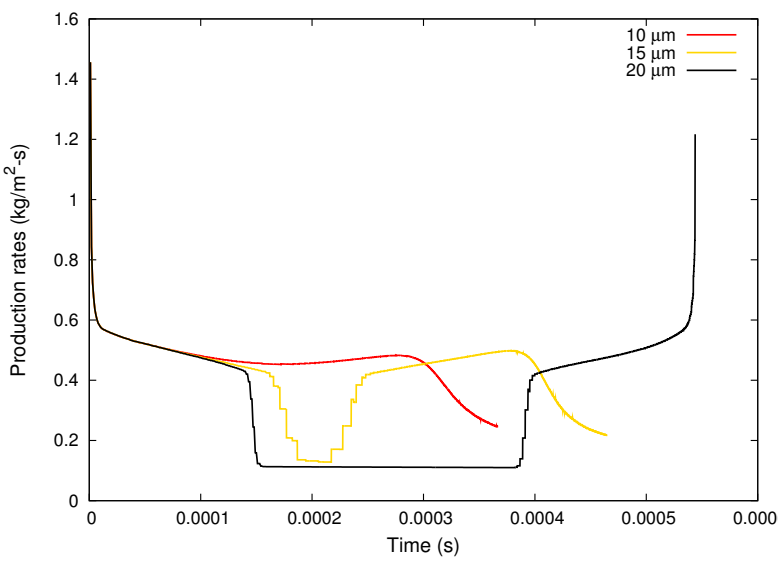

(b) Oxidation

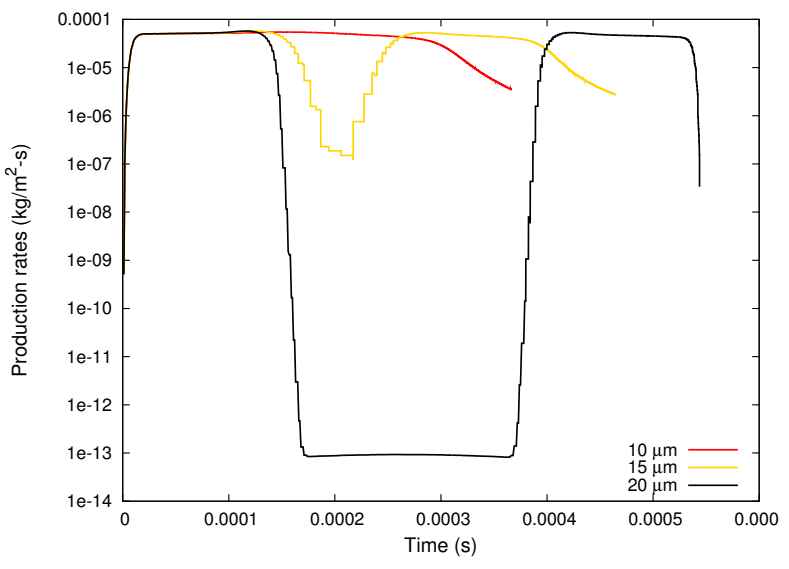

(c) Nitridation

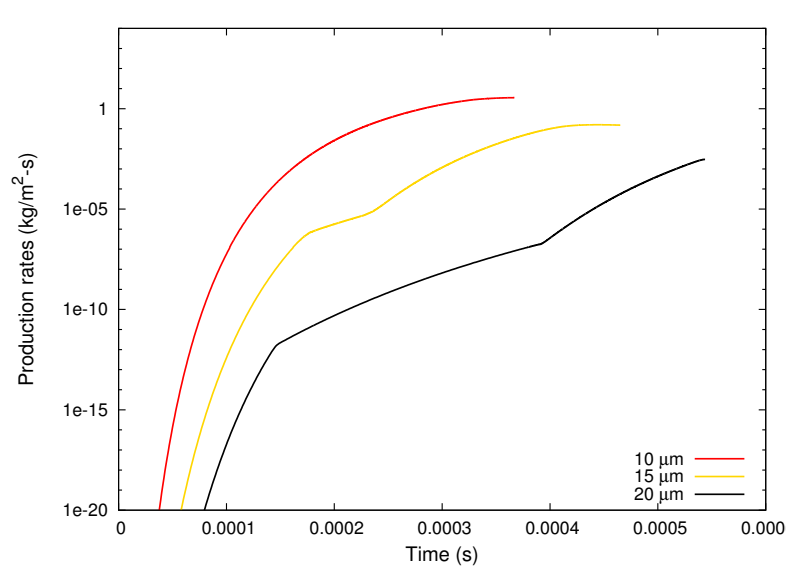

(d) Sublimation

Figure 6. Flow interactions for spalled particles of various size, ejected normal to the surface at $120 \mathrm{~m} / \mathrm{s}, 3$ $\mathrm{mm}$ from the center line

Figure 7(a) present the trajectories of spalled particle of size $30 \mu \mathrm{m}$ ejected at velocities $50 \mathrm{~m} / \mathrm{s}, 75$ $\mathrm{m} / \mathrm{s}$ and $90 \mathrm{~m} / \mathrm{s}$ normally from a point located $5 \mathrm{~mm}$ from the center axis. The trajectories of the spalled particle are similar to the one observed in the previous cases. Figure 7(b), (c) and (d) show the variation of production rates with the ejection velocities of the particle. As for the trajectories, the production rates are similar than for previous cases.

It can be deduced from Figure 6 and Figure 7 that the nitridation of the spalled particle hardly takes place and possible traces of $\mathrm{CN}$, as found by spectroscopic measurements in the shock layer, could be produced 
by oxidation product undergoing the following reactions

$$
\begin{gathered}
\mathrm{CO}+\mathrm{N} \rightleftharpoons \mathrm{CN}+\mathrm{O} \\
\mathrm{CO}+\mathrm{N}_{2} \rightleftharpoons \mathrm{CN}+\mathrm{NO}
\end{gathered}
$$

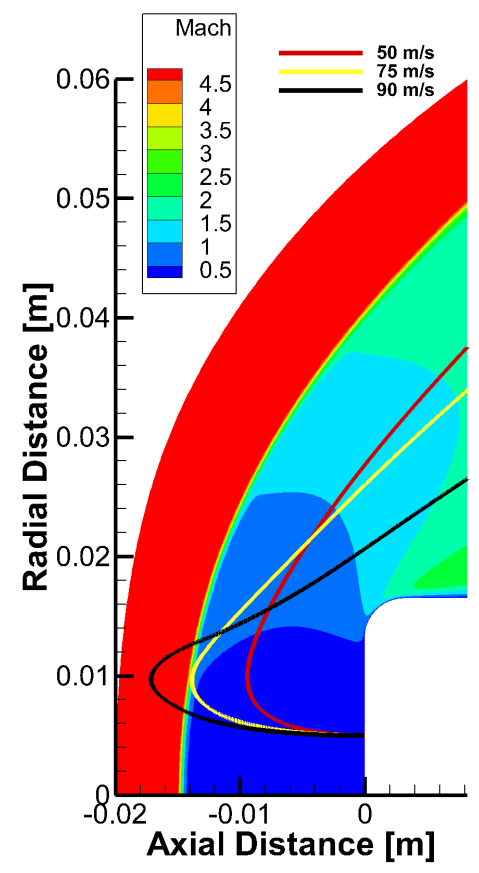

(a) Trajectory

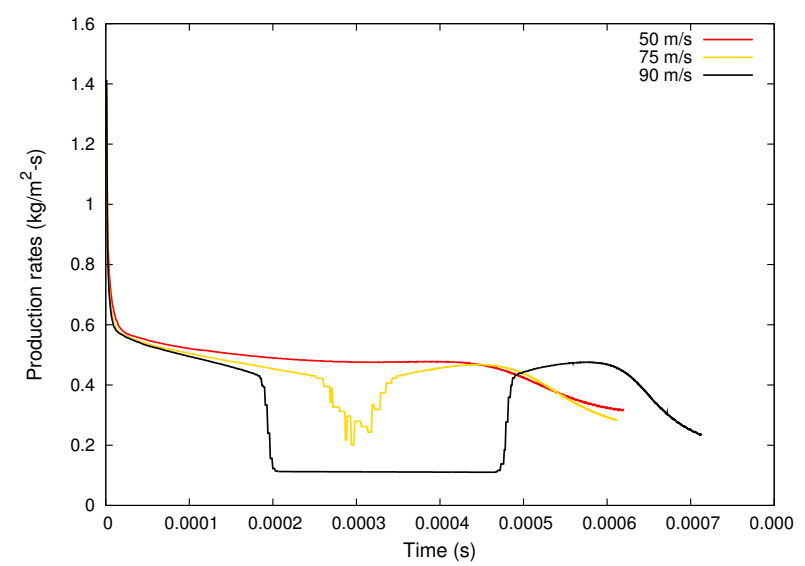

(b) Oxidation

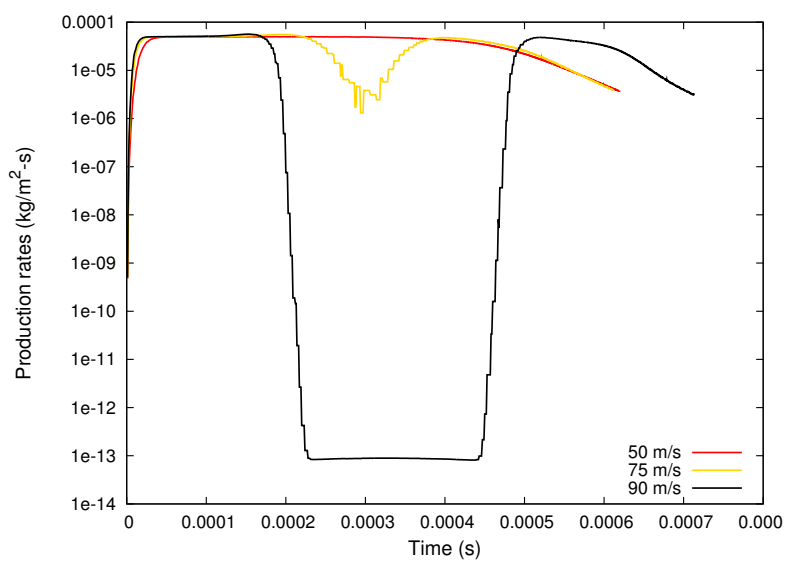

(c) Nitridation

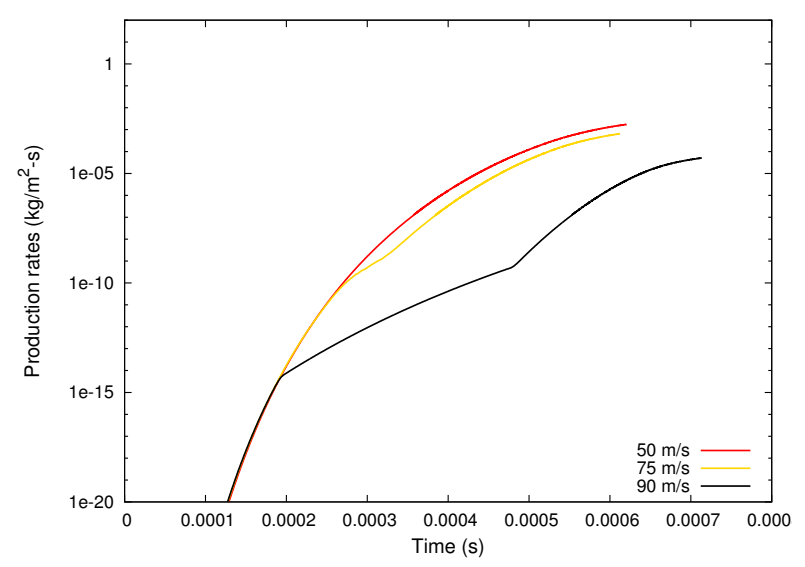

(d) Sublimation

Figure 7. Flow interactions for $30 \mu \mathrm{m}$ spalled particles of various initial velocities, ejected normal to the surface at $5 \mathrm{~mm}$ from the center line

The chemistry model used in this work is compared with Park's model. ${ }^{11,6,25}$ The values of $\gamma_{0}$ and $E$ for Park's chemistry model are given in Table 3. It considers the sublimation, and $\mathrm{C}_{3}$ is assumed to be the dominant species of sublimation. The comparison is therefore only made for $\mathrm{C}_{3}$ sublimation. For this test-case, a $12 \mu \mathrm{m}$ particle is ejected from an the surface $7 \mathrm{~mm}$ from the center axis, at a normal ejection velocity of $150 \mathrm{~m} / \mathrm{s}$. The comparative results are presented in Fig. 8. It is observed that although the particle traverses the same trajectory, the variation of its diameter and temperature along its path is different. The model used in this work vaporizes more than Park's model. The oxidation rates in Fig. 8(b) of the park model do not differ much with the present model except at the surface of the sample from where ejection 
takes place. The nitridation rates are approximately 100 times higher for Park's model, as seen in Fig 8(c). The high rates are due to the value of $\gamma_{0}$ for nitridation in Park model which is significantly higher. Since the sublimation rate is only a function of the temperature of the particle, it behave the same way for the two models, as can be seen in Fig. 8(d).

The significant difference between the nitridation rates, as mentioned earlier, is due to the high $\gamma_{0}$ value in Park's model. Recent experiments conducted by Zhang et. al. ${ }^{31}$ on a high-purity graphite clearly shows that this value is too high: the rate for nitridation reaction was found to be 100 times smaller than the one in Park's model. This confirms that a rate in order of magnitude similar to the one used by Driver et al. is probably more accurate.

Table 3. Values of $\gamma_{0}$ and $E$ for the following reactions according to Park's surface chemistry model

\begin{tabular}{ccc}
\hline Reaction & $\gamma_{0}$ & $E(\mathrm{~kJ} / \mathrm{mol})$ \\
\hline \hline $\mathrm{C}_{(\mathrm{s})}+\mathrm{O} \longrightarrow \mathrm{CO}$ & 0.63 & 9.644 \\
$2 \mathrm{C}_{(\mathrm{s})}+\mathrm{O}_{2} \longrightarrow 2 \mathrm{CO}$ & 0.50 & 0 \\
$\mathrm{C}_{(\mathrm{s})}+\mathrm{N} \longrightarrow \mathrm{CN}$ & 0.30 & 0 \\
$3 \mathrm{C}_{(\mathrm{s})} \longrightarrow \mathrm{C}_{3}$ & $5.19 \times 10^{13}\left(\gamma_{\text {sub }}\right)$ & 775.81 \\
\hline
\end{tabular}

\section{Conclusion}

A spallation code was developed to compute the dynamics and chemical interactions of spalled particles with the surrounding flow field. The code uses a solution field obtained from a hypersonic aerothermodynamic CFD code, through one-way coupling. The code was verified using method of manufactured solutions, which confirmed both correctness of the numerical implementation of the equations and the order accuracy of the discretization.

Results were obtained for a flow over an arc-jet sample, in arc-jet conditions, using argon and air. The minimum ejection velocities of the spalled particles needed to pass through the shock was calculated. It was observed that these velocities were very high for an argon flow and that particles greater than $16 \mu \mathrm{m}$ hardly vaporize as they reach the shock. In air flow, the minimum ejection velocities were approximately one-third of the ones calculated in argon flow.

The chemical behavior of the spalled particles upstream and downstream of the shock was also studied. The production rates of $\mathrm{CO}, \mathrm{CN}$, and carbon vapors $\left(\mathrm{C}_{1}, \mathrm{C}_{2}, \mathrm{C}_{3}\right)$ were numerically studied by varying the diameters and the ejection velocities. It was noted that the oxidation rates were high when compared to nitridation and sublimation rates. The chemistry model was also compared with Park's model, and it was seen that the oxidation and sublimation rates are approximately similar whereas, as expected, the nitridation rates were higher in Park's model.

In future works, an inverse problem methodology will be used to extract ejection properties by fitting experimental data.

\section{Acknowledgements}

Financial support for this work was provided by NASA Kentucky EPSCoR Award NNX10AV39A, and NASA award NNX13AN04A. The first author would like to thank Huai-Bao Zhang, graduate student at the University of Kentucky for contributing his CFD model for the research work.

\section{References}

${ }^{1}$ Wakefield, R. M. and Pitts, W. C., "Analysis of the Heat-Shield Experiment on the Pioneer-Venus Entry Probes," AIAA-80-1494, doi:10.2514/6.1980-1494.

${ }^{2}$ Balakrishnan, A. and Nicolet, W. E., "Galileo Probe Forebody Thermal Protection: Benchmark Heating Environment Calculations," AIAA-81-1072,

doi:10.2514/6.1981-1072. 


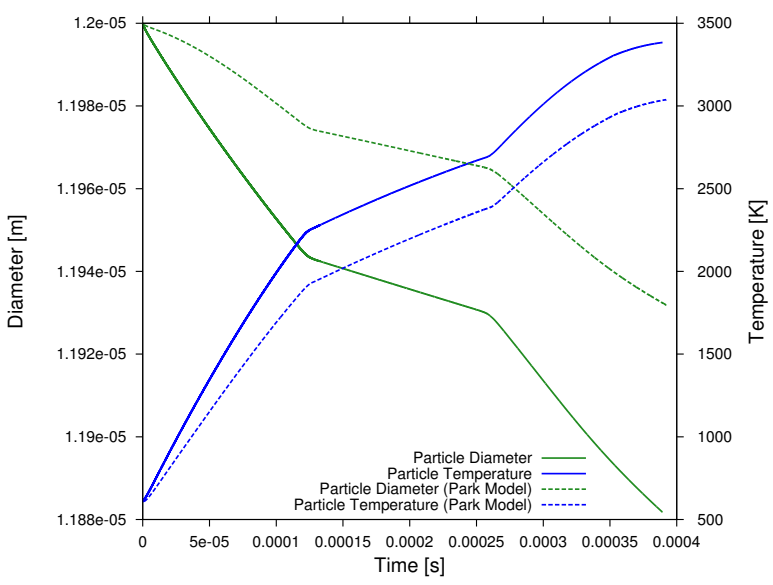

(a) Diameter and Temperature

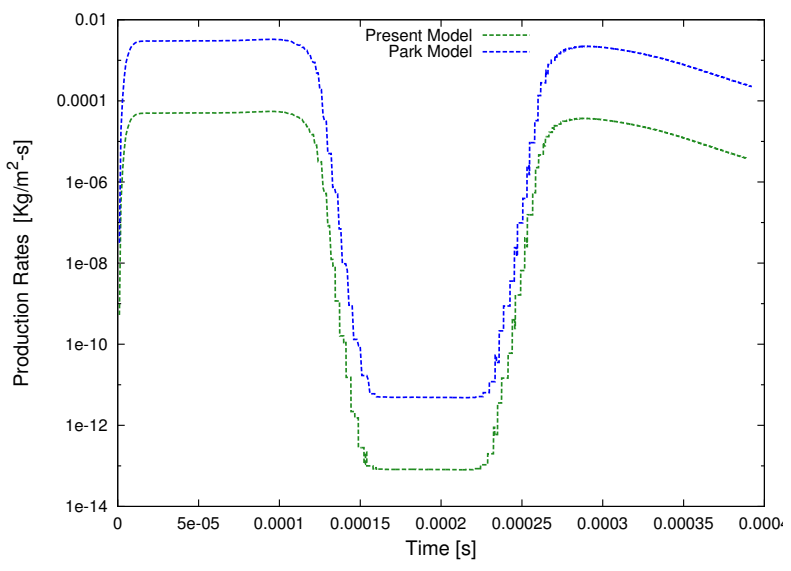

(c) Nitridation

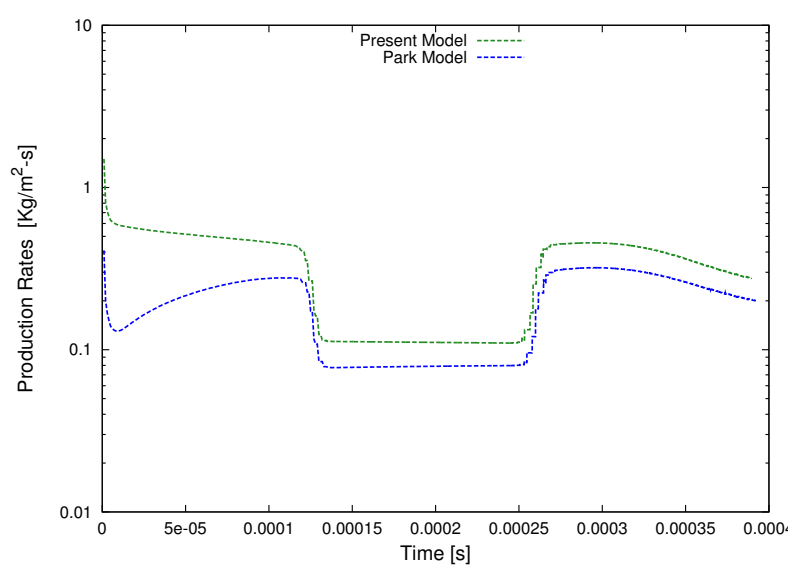

(b) Oxidation

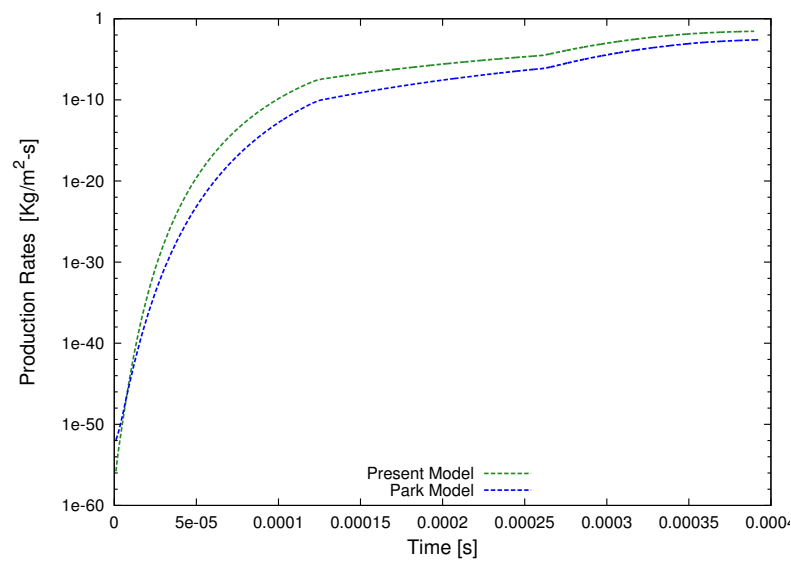

(d) Sublimation

Figure 8. Comparison of variation of diameter and temperature of particle and production rates of oxidation, nitridation and sublimation with Park ${ }^{11,6,25}$ Model 
${ }^{3}$ Milos, F. S., "Galileo Probe Heat Shield Ablation Experiment," Journal of Spacecraft and Rockets, Vol. 34, No. 6, 1997, pp. $705-713$,

doi:10.2514/2.3293.

${ }^{4}$ Moss, J. and Simmonds, A., "Galileo Probe Forebody Flowfield Predictions during Jupiter Entry," AIAA-1982-0874, doi:10.2514/6.1982-874.

${ }^{5}$ Raiche, G. and Driver, D., "Shock Layer Optical Attenuation and Emisssion Spectroscopy Measurements During Arc-Jet Testing with Ablating Models," AIAA-2004-825, doi:10.2514/6.2004-825.

${ }^{6}$ Park, C., II, G. A. R., and Driver, D. M., "Radiation of Spalled Particles in Shock Layers," Journal of Thermophysics and Heat Transfer, Vol. 18, No. 4, 2004, pp. 519-526, doi:10.2514/1.8098.

${ }^{7}$ Kihara, H., Hatano, M., Nakiyama, N., ichi Abe, K., and Nishida, M., "Preliminary Studies of Spallation Particles Ejected from an Ablator," Transactions of the Japan Society for Aeronautical and Space Sciences, Vol. 49, No. 164, 2006, pp. $65-70$,

doi:10.2322/tjsass.49.65.

${ }^{8}$ Yoshinaka, T., "Spallation Measurement at the Ablator Plasma Wind Tunnel Tests," Tech. Rep. NASDA-TMR-970006E, National Space Development Agency of Japan, Tokyo, 1998.

${ }^{9}$ Lundell, J. H., "Spallation of the Galileo Probe Heat Shield," AIAA-82-0852, doi:10.2514/6.1982-852.

${ }^{10}$ Davies, C. B. and Park, C., "Trajectories of Solid Particles Spalled From a Carbonaceous Heat Shield," AIAA-82-0200, doi:10.2514/6.1982-200.

${ }^{11}$ Park, C., "Interaction of Spalled Particles with Shock Layer Flow," Journal of Thermophysics and Heat Transfer, Vol. 13, No. 4, 1999, pp. 441-449, doi:10.2514/2.6482.

${ }^{12}$ Pace, A. E., Ruffin, S. M., and Barnhardt, M. D., "A Coupled Approach for Predicting radiation Attenuation in ParticleLaced Flows," AIAA 2011-3771,

doi:10.2514/6.2011-3771.

${ }^{13}$ Wright, M. J., Candler, G. V., and Bose, D., "Data-Parallel Line Relaxation Method for the Navier-Stokes Equations," AIAA, Vol. 36, No. 9, 1998, pp. 1603-1609, doi: $10.2514 / 2.586$.

${ }^{14}$ Nozawa, S., Kihara, H., and ichi Abe, K., "Numerical Investigation of Spalled Particle Behavior Ejected from an Ablator Surface," Transactions of the Japan Society for Aeronautical and Space Sciences, Vol. 8, No. 27, 2010, pp. Pe_9-Pe_14.

${ }^{15}$ Zhang, H.-B., Weng, H., and Martin, A., "Simulation of Flow-tube Oxidation on the Carbon Preform of PICA," AIAA 2014-1209, doi:10.2514/6.2014-1209.

${ }^{16}$ Henderson, C. B., "Drag Coefficients of Spheres in Continuum and Rarefied Flows," AIAA, Vol. 14, No. 6, 1976, pp. $707-708$, doi: $10.2514 / 3.61409$.

${ }^{17}$ Wilke, C. R., "A viscosity equation for gas mixtures," J. of Chem. Phys., Vol. 18, 1950, pp. 517-519, doi:10.1063/1.1747673.

${ }^{18}$ Blottner, F. G., Johnson, M., and Ellis, M., "Chemically reacting viscous flow program for multi-component gas mixtures," SC-RR-70-754, Sandia Laboratories.

${ }^{19}$ Carlson, D. J. and Hoglund, R. F., "Particle Drag and Heat Transfer in Rocket Nozzles," AIAA, Vol. 2, No. 11, 1964, pp. $1980-1984$ doi: $10.2514 / 3.2714$.

${ }^{20}$ Vincenti, W. G. and Kruger, C. H., Introduction to Physical Gas Dynamics, Krieger Publishing Company, 1982.

${ }^{21}$ Park, C., Nonequilibrium Hypersonic Aerothermodynamics, Wiley, New York, 1990.

${ }^{22}$ M. W. Chase, J., Davis, C. A., J. R. Downey, J., Frurip, D. J., McDonald, R. A., and Syverud, A. N., "JANAF Thermochemical Tables," Journal of Physical and Chemical Reference Data, Vol. 14.

${ }^{23}$ Driver, D. M. and MacLean, M., "Improved predictions of PICA Recession in Arc Jet Shear Tests," AIAA 2011-141, doi:10.2514/6.2011-141.

${ }^{24}$ Maclean, M., Marschall, J., and Driver, D. M., "Finite-Rate Surface Chemistry Model, II: Coupling to Viscous NavierStokes Code," AIAA 2011-3784, doi:10.2514/6.2011-3784.

${ }^{25}$ Park, C. and Bogdanoff, D. W., "Shock Tube Measurement of Coefficient of Reaction of Nitrogen Atoms and Solid Carbon: Preliminary Results," AIAA 2003-0158, doi:10.2514/6.2003-158.

${ }^{26}$ Baker, R. L., "Graphite Sublimation Chemistry Nonequilibrium Effects," AIAA, Vol. 15, No. 10, 1977, pp. 1391-1397, doi:10.2514/3.60806.

${ }^{27}$ Pflieger, R., Sheindlin, M., and Colle, J. Y., "Advances in the Mass Spectrometric Studies of the Laser-Induced Vaporisations of Graphit and Uranium Dioxide," in "European Conference on Thermophysical Properties," Bratislava, Slovak Republic, 2005.

${ }^{28}$ Palmer, H. B. and Shelef, M., "Vaporization of Carbon," in Walker, P., Jr, ed., "Chemistry and Physics of Carbon," Marcel Dekker, Inc., New York, Vol. 4, 1968.

${ }^{29}$ Weng, H. and Martin, A., "Multi-dimensional modeling pyrolysis gas flow inside charring ablators," AIAA 2013-2635, doi:10.2514/6.2013-2635. 
${ }^{30}$ Roy, C., Ober, C., and Smith, T., "Verification of a Compressible CFD Code Using the Method of Manufactured Solutions," AIAA 2002-3110, doi:doi:10.2514/6.2002-3110.

${ }^{31}$ Zhang, L., Pejakovic, D. A., Marschall, J., Dougherty, M., and Fletcher, D., "Laboratory Investigation of the Active Nitridation of Graphite by Atomic Nitrogen," Journal of Thermophysics and Heat Transfer, Vol. 26, No. 1, 2012, pp. 10-21, doi:10.2514/1.T3612. 